\title{
STRATEGI PEMASARAN DALAM REKRUTMEN PESERTA DIDIK BARU DI MADRASAH IBTIDAIYAH MA'ARIF (MIMA) O1 KH. SHIDDIQ JEMBER
}

\author{
Silfiyah Aisyatul Maziyah \\ SMA Islam Al-Hidayah Mangli Jember \\ silfiyah.aisyah@yahoo.com \\ Khotibul Umam \\ IAIN Jember \\ khotibulumam.ma@gmail.com \\ Hepni \\ IAIN Jember \\ hefnizn@gmail.com
}

DOI: https://doi.org/10.35719/jieman.v2i1.19

\begin{abstract}
Abstrak
Salah satu upaya untuk menjamin kelansungan lembaga pendidikan adalah strategi pemasaran yang tepat sasaran dalam jangka pendek, jangka menengah dan jangka panjang. Kajian ini difokuskan untuk mengungkap: 1) Bagaimana konsep perencanaan pemasaran dalam rekutmen peserta didik baru di MIMA o1 KH. Shiddiq Jember Tahun Pelajaran 2018/2019? 2) Bagaimana pelaksanaan pemasaran dalam rekutmen peserta didik baru di MIMA o1 KH. Shiddiq Jember Tahun Pelajaran 2018/2019? 3) Bagaimana faktor pendukung dan kendala pemasaran dalam rekutmen peserta didik baru di MIMA o1 KH. Shiddiq Jember Tahun Pelajaran 2018/2019? Pendekatan penelitian menggunakan pendekatan kualitatif. Pengumpulan data menggunakan observasi, wawancara dan dokumentasi. Analisis data menggunakan teknik analisis interaktif model Miles and Huberman yaitu pengumpulan data, kondensasi data, penyajian data dan penarikan kesimpulan. Teknik pengumpulan data menggunakan observasi partisipan, wawancara terbuka dan dokumentasi. Pengecekan keabsahan data memakai uji kredibilitas yaitu triangulasi sumber dan metode. Hasil penelitian adalah
\end{abstract}


1) Konsep perencanaan strategi pemasaran dalam rekrutmen peserta didik baru menggunakan bauran pemasaran 4-P; konsep product, price, promotion, place. 2) Pelaksanaan pemasaran dalam rekrutmen peserta didik baru menggunakan identifikasi pasar, segmentasi pasar dan positioning. 3) Faktor pendukung pemasaran yaitu menjalin kepercayaan kepada masyarakat dan kendala pemasaran terdapat pada minimnya akses media informasi lembaga.

Kata Kunci: madrasah ibtidaiyah, rekrutmen peserta didik, strategi pemasaran sekolah

\begin{abstract}
One of the efforts to ensure the existence of educational institutions is a targeted marketing strategy in the short term, the medium term and the long term. The study is focused on uncovering: 1) how the concept of marketing planning in the new protege program at MIMA o1 KH. Shiddiq Jember of lesson 2018/2019? 2) how is marketing performed in the new education program at MIMA o1 KH. Shiddiq Jember lesson 2018/2019? 3) how are contributing factors and marketing constraints in the new advanced education program at MIMA o1 KH. Shiddiq Jember of 2018/2019? The research approach employs a qualitative approach. Data collection uses observation, interview and documentation. Data analysis uses the Miles, Huberman and Saldana's interactive model analysis techniques that are data collecting, data condensing, data presentation and deduction pullout. Data gathering techniques using participants' observations, open interviews and documentation. Verifying data results in a credibility test, which is source and method triangulation. Research results are 1) The concept of marketing strategy planning in new recruits using 4-p marketing mix: product, price, promotion, place. 2) Implementation of marketing in the new protege recruits using market identification, market segmentation and positioning. 3) The marketing factor of developing trust in people and marketing challenges is that the society's lack of access to media information.
\end{abstract}

Keywords: Islamic elementary school, school marketing strategy, students' recruitment

\title{
Pendahuluan
}

Sebuah organisasi dapat mempertahankan sebuah program unggulannya tidak mudah jika tidak ada sebuah rancangan khusus atau strategi khas yang mampu dipertanggung jawabkan dalam menjalankan visi misinya. Dibutuhkan sebuah kerjasama dengan masyarakat luas dalam mempromosikan serta komitmen mempertahankan sebuah produk unggulan dalam memasarkan program di kalangan masyarakat. 
American Marketing Association (AMA) menyebutkan: Marketing as a function and a series of processes for creating, communicating and providing value to customers and managing customer relationships in a way that benefits organizations and stakeholders while Phillip Kotler raises marketing, namely humans who are directed at efforts to meet needs through an exchange process. (Pemasaran merupakan suatu fungsi dan serangkaian proses untuk menciptakan, mengkomunikasikan dan memberikan nilai kepada pelanggan dan mengelola hubungan pelanggan dengan cara menguntungkan organisasi danpemangku kepentingan sedangkan Phillip Kotler mengemukaakan pemasaran yaitu manusia yang diarahkan pada usaha untuk memenuhi kebutuhan melalui proses pertukaran). ${ }^{1}$

Hidayat dan Machali dalam buku Pengelolaan Pendidikan Pertama mendefinisikan pemasaran sebagai suatu proses sosial dan manjerial yang melibatkan beberapa kegiatan penting yang memungkinkan individu dan kelompok mendapatkan kebutuhan dan keinginan melalui pertukaran dengan pihak lain dan mengembangkan relasi, di antaranya proses pemasaran melibatkan sosial, budaya, politik, ekonomi dan manjerial.Terdapat pengaruh dari individu di antaranya mendapatkan kebutuhan dan keinginan mereka dengan menciptakan, menawarkan dan bertukar satu sama lain. $^{2}$

Kotler dan Keller juga mengatakan bahwa strategi pemasaran yaitu merupakan suatu pola pikir mengenai pemasaran yang digunakan untuk mencapai tujuan pemasarannya. Startegi pemasaran berisi mengenai strategi spesifik untuk pasar sasaran, penetapan posisi, bauran pemasaran dan besarnya pengeluaran pemasaran. $^{3}$ Dengan demikian, pemasaran jasa seperti jasa lembaga pendidikan terkait pada konsep permintaan, produk, nilai dan kepuasan pelanggan. ${ }^{4}$

${ }^{1}$ Phillip Kotler dan Kevin Lane Keller. Manajemen Pemasaran Edisi Ketiga Belas Jilid I. (Jakarta : Erlangga, 2008), 1

${ }^{2}$ Ara Hidayat dan Imam Machali. Pengelolaan Pendidikan Pertama. (Bandung : Pustaka Educa, 2010).

${ }^{3}$ Phillip Kotler dan Kevin Lane Keller. Manajemen Pemasaran, 2

${ }^{4}$ Yeti Heryati dan Mumuh Muhsin. Manajemen Sumber Daya Pendidikan. (Bandung: CV. Pustaka Setia, 2014), 260 
Kegiatan pemasaran dengan melakukan inovasi pemasaran serta menemukan strategi pemasaran yang paling tepat. Jadi, pemasaran merupakan suatu proses sosial dan manajerial yang melibatkan individu dan kelompok mendapatkan kebutuhan dan keinginan mereka dengan menciptakan, menawarkan dan bertukar satu sama lain dan pemasaran tidak hanya berfungsi menyampaikan produk atau jasa terdapat kepuasan pelanggan.

Dalam konteks pendidikan, hal yang paling penting untuk ditanamkan kepada anak sejak dini terdapat pada peran ayah dalam keluarga dan peran ibu dalam keluarga adalah untuk mengajarkan agama secara tepat kepada anak. Ayah dan ibu wajib memberi pendidikan agama kepada anak sejak dini, cara mendidik anak dalam agama bisa dimulai ketika anak diajarkan mengenai hal-hal yang mendasar terlebih seperti shalat lima waktu, berpuasa, bersedekah dan hal-hal yang menyangkut kehidupan beragama sehari-hari terutama orang tua adalah untuk mendidik anak dengan sebaik-baiknya menurut nilai-nilai kehidupan yang baik yang telah mereka ketahui. Hal ini tentu berguna agar anak kelak tumbuh menjadi pribadi yang memiliki ciri-ciri orang baik hati dan memahami ajaran agama dengan baik sehingga bisa melandasi kehidupannya dengan pengetahuan agama.

Di antara manusia ada yang lebih mengutamakan hal yang dhahir di dunia dan melupakan urusan yang besar tentang akhirat atau agama. Akhirnya banyak di antara orang tua yang rela mengeluarkan banyak harta untuk membiayai anaknya les Matematika, les komputer, dan ketrampilan lainnya, namun tidak pernah memikirkan bagaimana bacaan Al-Qur'an yang tepat dan benar untuk buah hatinya.

Terdapat dalam surah QS. Ar-Rum ayat 7 yang menerangkan kita terhindar dari sikap orang kafir terhadap dunia, Allah SWT berfirman:

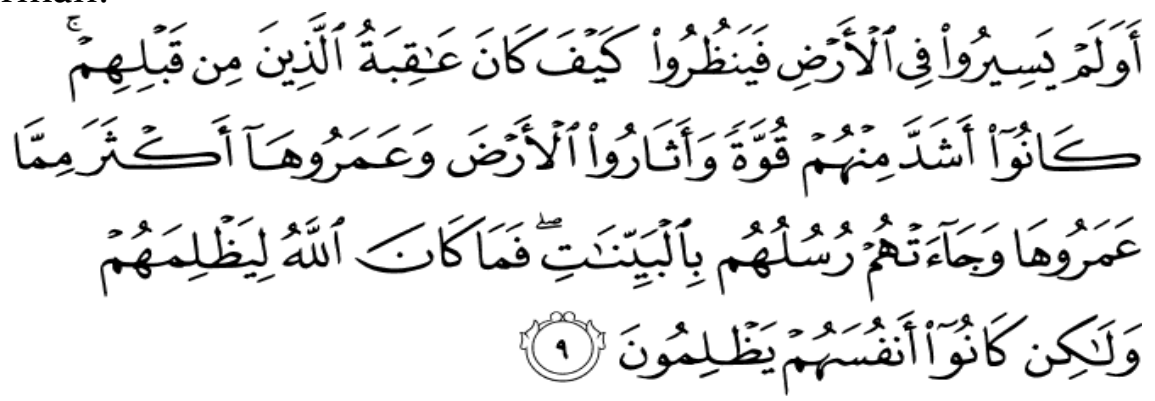


Terjemah: "Mereka hanya mengetahui yang lahir (saja) dari kehidupan dunia, sedang mereka tentang (kehidupan) akhirat adalah lalai”. (Qs.Ar - Rum :7). ${ }^{5}$

Ath Thobari menyebutkan sebuah riwayat dari Ibnu 'Abbas yang menerangkan mengenai maksud ayat di atas. Yang dimaksud dalam ayat itu adalah orang-orang kafir. Mereka benar-benar mengetahui berbagai seluk beluk dunia. Namun terhadap urusan agama, mereka benar-benar bodoh (jahil). ${ }^{6}$ berikut:

Fakhruddin Ar-Razi menjelaskan maksud ayat itu sebagai

"Ilmu mereka hanyalah terbatas pada dunia saja. Namun mereka tak mengetahui dunia dengan sebenarnya. Mereka hanya mengetahui dunia secara lahiriyah saja yaitu mengetahui kesenangan dan permainannya yang ada. Mereka tak mengetahui dunia secara batin, yaitu mereka tak tahu bahaya dunia dan tak tahu kalau dunia itu terlaknat. Mereka memang hanya mengetahui dunia secara lahir, namun tak mengetahui kalau dunia itu akan fana."

Kajian ini dilakukan untuk menjawab bagaimana konsep perencanaan, pelaksanaan serta faktor pendukung dan kendala pemasaran dalam rekrutmen peserta didik baru di MIMA or $\mathrm{KH}$. Shiddiq Jember, dengan metode penelitian kualitatif dengan jenis fenomenologi. Penulis hendak memahami dan mengungkap suatu fenomena beserta konteksnya yang khas dan unik yang dialami oleh individu hingga tataran "keyakinan" individu yang bersangkutan.

\section{Pembahasan}

Konsep Perencanaan Pemasaran Rekrutmen Peserta Didik Baru di MIMA o1 KH. Shiddiq Jember

Konsep strategi pemasaran MIMA or KH. Shiddiq adalah dengan mengadakan pertemuan agenda tahunan yang diawali Restu, 1976)

${ }^{5}$ Al-Qur'an dan Terjemahannya. Departemen Agama RI. (Jakarta: Bumi

${ }^{6}$ Ath-Thabari, Abu Ja'far Muhammad bin Jarir, Jamiee Al- Bayan an Ta"ewil Ayi Al-Qurean. Penerjemah: Abdul Somad, Yusuf Hamdani, dkk, jilid 3, 12, 13, 21. (Jakarta: Pustaka Azzam, 2008)

${ }^{7}$ Fakhr al-Din al-Razi.Tafsir al-Kabir wa Mafatih al-Ghaib Jilid 1o. (Dar al Kutub al-Ilmiah, Beirut, t.th) 
dengan pembentukan rapat panitia Penerimaan Peserta Didik Baru (PPDB) dengan agenda lomba Musabaqoh Tartil dan Tahfidh AlQur'an (MT2Q) yang diadakan setiap awal tahun ajaran baru kemudian Kepala Madrasah mengorganisasikan beberapa pendidik yang terlibat untuk segera menyebar brosur ke beberapa lembaga instansi TK di Kabupaten Jember. Kemudian media pemasaran lain seperti banner dipasang di sepanjang jalan terutama di pusat kota terkait dengan PPDB.

Temuan tersebut digolongkan berdasarkan beberapa persyaratan dalam bauran pemasaran yang dipopulerkan oleh Jerome McCarthy terdapat empat aspek pokok, yaitu: product, price, promotion dan place. ${ }^{8}$

1. Produk (Product)

Produk jasa menurut Kotler merupakan segala sesuatu yang dapat ditawarkan produsen untuk diperhatikan, diminta, dicari, dibeli digunakan atau dikonsumsi pasar sebagai pemenuhan kebutuhan atau keinginan pasar yang bersangkutan.

Konsumen sesungguhnya tidak membeli barang atau jasa tetapi membeli manfaat dan nilai dari sesuatu yang ditawarkan. MIMA o1 KH. Shiddiq Jember menawarkan produk unggulan yang diadakan setiap tahunnya, manfaatnya masyarakat selain mendapatkan pahala dalam melantunkan ayat suci Al-Qur'an dan juga menjalin silahturahmi pada program Musabaqah Tartil dan Tahfidh Al-Qur'an (MT2Q).

Suatu produk dapat berupa suatu benda, jasa dan keinginan lainnya unruk melukiskan sesuatu yang dapat memenuhi keinginan. Setiap pengusaha mengetahui perkembangan kebutuhan konsumen melaui penelitian lapangan agar dapat mengetahui dan menyesuaikan kebutuhan produk yang akan di tawarkan. Demikian halnya dengan pengelola lembaga Pendidikan.

Kegiatan yang terdapat dalam MIMA o1 KH. Shiddiq Jember setiap tahunnya Kepala Madrasah bersama Panitia PPDB mengadakan program tahunan sekolah dengan melibatkan masyarakat disetiap tahun ajaran baru dan memberikan reward bagi calon peserta didik mengikuti event tahunan lomba Tartil dan Tahfidh Al-Qur'an (MT2Q) akan dibebaskan serangkaian seleksi PPDB.

2. Harga (Price)

8 Buchari Alma dan Ratih Hurriyati. Manajemen Coorporate dan Strategi Pemasaran Pendidikan Fokus Pada Mutu dan Layanan Prima. (Bandung : Alfabeta, 2008), 161 
Harga merupakan indikator dari barang dalam menetapkan harga diperlukan sangat ketelitian dan hati-hati dalam memperhatikan potensi pasar. Kebijakan yang ditetapkan oleh Kepala Madrasah bersama Panitia PPDB memberitahu orangtua calon peserta didik akan dikenakan administrasi awal sebesar Rp. 150.00o,- dan bagi calon peserta didik yang dinyatakan juara I akan mendapatkan gratis pendaftaran awal dan SPP selama 9 bulan dan juara II mendapatkan gratis SPP selama 6 bulan pertama di MIMA o1 KH. Shiddiq Jember.

Data di atas menunjukkan bahwa MIMA o1 KH. Shiddiq Jember mengombinasikan tiga prindip pemasaran sebagaimana yang dikemukan Kotler dan Keller, yaitu: penentapan harga berdasarkan biaya (cost-based pricing), penetapan harga berdasarkan persaingan (competetion-based pricing), dan penetapan harga berdasarkan permintaan (demand-based pricing). ${ }^{9}$

\section{Promosi (Promotion)}

Penyebaran informasi pemasaran sekolah di MIMA KH. Shiddiq Kabuten Jember dilakukan Panitia PPDB menggunakan media sosial seperti grup WhatsApp KKG (Kelompok Kerja Guru) dan pengumuman Musabaqah Tartil dan Tahfidh Al-Qur'an (MT2Q) Kepala Madrasah dan menggunakan media cetak seperti brosur, pamflet dan memasang banner/baliho di tempat strategis yang dapat dilihat masyarakat sekitar.

Temuan ini sejalan dengan pendapat Buchari Alma dan Ratih Huriyati dalam buku Manajemen Coorporate dan Strategi Pemasaran Jasa Pendidikan (Fokus Pada Mutu Layanan Prima). Menurut keduanya, hakikat dari promosi adalah ikhtiar menyebarkan informasi, mempengaruhi/membujuk, mengingatkan pasar sasaran atas perusahaan dan produknya agar bersedia menerima, membeli dan loyal pada produk yang ditawarkan. ${ }^{10}$

\section{Tempat/Distribusi (Place)}

Produk yang ditawarkan oleh suatu organisasi akan lebih berguna bagi konsumen/pembeli apabila produk tersebut tesedia pada tempat dan saat dimana saja dibutuhkan atau mudah di-

${ }^{9}$ Phillip Kotler dan Kevin Lane Keller. Manajemen Pemasaran, 56.

${ }^{10}$ Buchari Alma dan Ratih Hurriyati. Manajemen Coorporate dan Strategi Pemasaran Jasa Pendidikan (Fokus Pada Mutu Layanan Prima). (Bandung : Alfabeta, 2008), 163 
jangkau oleh peminatnya. Lokasi pendaftaran PPDB (Penerimaan Peserta Didik Baru) diadakan di kantor Tata Usaha MIMA o1 KH. Shiddiq Jember Jl. KH. Shiddiq No. 42 Kulon Pasar Tanjung Jember Kidul Kaliwates Jember.

Untuk menjalain komunikasi yang baik dengan pelanggan (masyarakat) maka diperlukan menjaga hubungan dengan baik. Jika sudah menjalin komunikasi dua arah dengan positif maka langkah dalam melaksankan tugas sesuai dengan tujuan awal. Hal ini sesuain dengan pendapat sebagaimana yang kutip oleh Suryobroto Public Relations atau disebut sebagai hubungan masyarakat dalam buku Hubungan Sekolah dengan Masyarakat (School Public Relations). Hubungan masyarakat adalah salah satu bagian dari upaya membentuk dan memelihara relasi yang saling menguntungkan antara organisasi dengan publiknya. Keberhasilan atau kegagalan public relations bergantung bagaimana kiat membentuk dan memelihara relasi tersebut ${ }^{11}$ Dalam suatu organisasi pendidikan atau pendidikan Islam, pada hakikatnya tanpa adanya public relations sudah dapat berjalan, namun dengan tertatih-tatih dan tidak mampu berkembang dengan baik.

Berdasarkan paparan data di atas konsep perencanaan pemasaran sekolah di MIMA or KH. Shiddiq Jember perlu dilakukan untuk memenuhi dan memberikan pelayanan yang prima kepada pelanggan (masyarakat). Dengan adanya konsep perencanaan pemasaran sekolah akan menjadikan pemasaran sekolah menjadi berkualitas.

\section{Pelaksanaan Pemasaran dalam Rekrutmen Peserta Didik di MIMA o1 KH. Shiddiq Jember}

Untuk mengetahui kegiatan pemasaran sekolah telah diadakan Identifikasi pasar dengan memperhatikan 2 aspek di antaranya Kekuatan (Strenght-S), Kelemahan (Weakness-W), Peluang (Opportunities-O), Ancaman (Treats-T) dan terakhir diadakan Segmentasi pasar dan positioningdengan menggunakan pendekatan pertama, diferensi Produk dan kedua, komunikasi pemasaran. Dalam konteks ini MIMA or Kh. Shiddiq Jember melakukan berbagai tahapan dalam mendekati pelanggan (masyarakat). Hal tersebut diungkapkan oleh teori yang mendukung terkait dengan rekrutmen peserta didik baru.

"Mujamil Qomar. Manajemen Pendidikan Islam: Strategi Baru Pengelolaan Lembaga Pendidikan Islam (Jakarta: Erlangga, 2007), 32. 
Sasaran pemasaran lembaga pendidikan adalah calon peserta didik dan orang tua peserta didik, serta masyarakat luas pada umumnya, Masyarakat luas termasuk di dalamnya pengguna lulusan. Menurut Davies dan Ellison sebagaimana yang kutip dari buku School Development Planning Market segments in the education sector include internal markets and external markets. The internal market includes school managers and the ranks above, school staff (teachers and other education personnel), supervisors, students who are attending school parents of students who are in school. Segmen pasar di sektor pendidikan meliputi pasar internal dan pasar eksternal. Pasar internal meliputi pengelola sekolah dan jajaran di atasnya, staf sekolah (guru dan tenaga kependidikan lainnya), pengawas, siswa yang sedang bersekolah orang tua siswa yang sedang bersekolah. ${ }^{12}$

Untuk mencapai kontrol baik, masyarakat membutuhkan informasi yang cukup akurat dan memadai dan bagi Madrasah dapat dijadikan sebagai acuan dalam pelaksanaan dan evaluasi.Tahapan pelaksana dan pengelolaan dalam strategi pemasaran harus memperhatikan perancangan organisasi pemasaran yang efektif.

Pelaksanaan pemasaran sekolah menurut Yeti Heryati dan Mumuh Muhsin yang dikutip dari buku Manajemen Sumber Daya Pendidikan, yaitu: ${ }^{13}$

1. Identifikasi Pasar

Dalam tahap ini, MIMA or Kh. Shiddiq Jember terletak pada ciri khas slogan brosur lomba Musabaqah Tartil dan Tahfidh AlQur'an (MT2Q), sehingga masyarakat mudah memahami bahwa MIMA o1 KH. Shiddiq Jember yang menyelenggarakan event tersebut. Menurut Kompri yang dikutip dari buku Motivasi Pembelajaran Perspektif Guru dan Siswa analisis yang strategis yaitu dengan analisis SWOT: ${ }^{14}$ Dengan memperhatikan aspek:

a. Kekuatan (Strenght-S): konsisten terhadap program yang diselenggarakan setiap tahunnya

${ }^{12}$ B. Davies dan Ellison, L. School Development Planning. (Essex: Longman Group U.K.Ltd, 1992).

${ }^{13}$ Yeti Heryati dan Mumuh Muhsin. Manajemen Sumber Daya Pendidikan. (Bandung: CV. Pustaka Setia, 2014), $261-262$

${ }^{14}$ Kompri. Motivasi Pembelajaran Perspektif Guru dan Siswa. (Bandung:

PT Remaja Rosdakarya Offset, 2015), 49 - 50 
b. Kelemahan (Weakness-W): Tidak tersedianya struktur kehumasan dalammelaksanakan strategi pemasaran sekolah.

c. Peluang (Opportunities-O): Bagi calon peserta didik yang berprestasi di lomba $\mathrm{MT} 2 \mathrm{Q}$ diberikan hadiah menjadi calon peserta didik tanpa mengikuti tes. Ditambah dengan calon peserta didik baru mendapatkan hadiah berupa gratis pendaftaran hingga SPP selama 6 - 9 bulan.

d. Ancaman (Treats-T): Memiliki kesamaan dengan lembaga lain dalam menerapkan konsep strategi pemasaran sekolah.

2. Segmentasi Pasar dan Positioning

a. Diferensi Produk

Diferensiasi produk MIMA o1 KH. Shiddiq Jember terletak pada ciri khas slogan brosur lomba Musabaqah Tartil dan Tahfidh Al-Qur'an (MT2Q), sehingga masyarakat mudah memahami bahwa MIMA o1 KH. Shiddiq Jember yang menyelenggarakan event tersebut

b. Komunikasi Pemasaran

Ada lima teknik komunikasi yang dilakukan oleh MIMA o1 KH. Shiddiq Jember. Pertama, penjualan pribadi (personal selling). Panitia PPDB membuat teknik menjajaki target sasaran dengen mengunjugi RA dan TK di Kabupaten Jember serta memberdayakan Alumni untuk menyebarluaskan informasi terkait agenda sekolah dan PPDB.

Kedua, penjualan massal (mass selling). Panitia PPDB menjalin komunikasi dengan masyarat menggunakan media cetak seperti brosur, banner / baliho di pasang di seluruh pemukiman padat penduduk dan menggunakan media sosial seperti WhatsApp, facebook dan website resmi MIMA o1 KH. Shiddiq Jember.

Ketiga, promosi penjualan (sales promotion). Panitia PPDB menjalin komunikasi dengan masyarakat menggunakan media cetak seperti brosur, banner / baliho di pasang di seluruh pemukiman padat penduduk dan menggunakan media sosial seperti WhatsApp, facebook dan website resmi MIMA o1 KH. Shiddiq Jember sebagai sarana penghubung komunikasi untuk masyarakat yang jauh dengan lokasi lembaga kami 
Keempat, hubungan masyarakat (public relations). Ciri khasnya panitia PPDB mengunjungi RA dan TK Se Kabupaten Jember untuk mendekati masyarakat

Kelima, dari mulut ke mulut (word of mouth). Sekolah yang dibuat oleh Kepala MIMA o1 KH. Shiddiq Jember bersama para pendidikmenggunakan komunikasi dua orang atau lebih disekitar lingkungan tempat tinggal.

Apa yang dilakukan oleh MIMA o1 KH. Shiddiq Jember sejalan dengan pendapat Alma dan Huriyati yang membagi bentuk komunikasi pemasaran menjadi lima macam: penjualan pribadi (personal selling), penjualan massal (mass selling), promosi penjualan (sales promotion), hubungan masyarakat (public relations), dan dari mulut ke mulut (word of mouth). ${ }^{15}$

Hal ini sekaligus memperkuat teori citra yang dikemukakan Frank Jefkins. Citra dalam konteks humas merupakan sebuah kesan, gambaran, atau impresi yang tepat. Impresi yang tepat dimaksudkan sebagai pernyataan yang sesuai dengan kenyataan. Impresi tersebut merupakan bentuk keberadaan dari berbagai kebijakan para personil atau jasa-jasa dari suatu organisasi atau perusahaan.

Jika dikaitkan dalam aspek hubungan masyarakat dengan strategi pemasaran sekolah, Frank Jefkins berpendapat hubungan masyarakat yaitu sesuatu yang merangkum keseluruhan komunikasi yang terencana baik dari dalam maupun dari luar organisasi dengan khalayak dalam rangka mencapai tujuan-tujuan tertentu. ${ }^{16}$ Fungsi hubungan masyarakat secara khas yaitu organisasi dengan masyarakatnya seperti lembaga pendidikan seperti guru, karyawan, peserta didik, masyarakat, wali murid, masyarakat, institusi luar dan partner sekolah.

Lembaga Pendidikan dikatakan maju apabila sumber daya manusianya (pendidik, tenaga kependidikan dan pelanggan jasa pendidikan) saling bersinergi dan mendukung keutamaan visi dan misi sekolah dan tujuannya memudahkan akses mencari pendidi-

${ }^{15}$ Buchari Alma dan Ratih Hurriyati. Manajemen Coorporate dan Strategi Pemasaran Jasa Pendidikan (Fokus Pada Mutu Layanan Prima). (Bandung : Alfabeta, 2008), 163

${ }^{16}$ Frank Jefkins (Daniel Yadin). Public Relations (Ahli Bahasa : Haris Munandar). (Jakarta : Erlangga, 1995), 9 
kan baik religius dan akademiknya menggunakan identifikasi pasar dan segmentasi pasar dan positioning.

Dalam pelaksanaan pemasaran sekolah dalam rekrutmen peserta didik, MIMA o1 KH. Shiddiq Jember memakai media sosial dan media cetak seperti brosur, baliho/banner dan pamflet bahkan promosi melalui para pendidik, perseorangan/kolega dan orang lain menggunakan identifikasi pasar dan segmentasi pasar dan positioning.

Berdasarkan paparan data di atas konsep perencanaan pemasaran sekolah di MIMA or KH. Shiddiq Jember perlu dilakukan untuk memenuhi dan memberikan pelayanan yang prima kepada pelanggannya (masyarakat). Dengan adanya pelaksanaan pemasaran sekolah akan menjadikan pemasaran sekolah menjadi berkualitas.

\section{Faktor Pendukung dan Kendala Pemasaran dalam Rekrutmen Peserta Didik Baru di MIMA o1 KH. Shiddiq Jember}

Untuk mengetahui kegiatan pemasaran sekolah telah diadakan perencanaan pemasaran sekolah dan pelaksanaan pemasaran sekolah dan harus memperhatikan lingkungan sekitar seperti faktor pendukung dan kendala pemasaran sekolah.

Lingkungan pemasaran terdiri dari kekuatan dari luar staf bagian pemasaran yang mempengaruhi kemampuan untuk mengembangkan dan mempertahankan hubungan baik dengan pelanggan sasaran. Kotler dan Amstrong mengatakan:

"The marketing environment consists of a micro environment and a macro environment. The micro environment consists of various forces close to the company that affect its ability to serve its customers, companies, suppliers, marketing channel companies, customer markets, competitors, and society. The macro environment consists of broader community strengths that affect the micro-demographic, economic, natural, technological, political and cultural environment" (Lingkungan pemasaran terdiri dari lingkungan mikro dan lingkungan makro. Lingkungan mikro terdiri dari berbagai kekuatan dekat dengan perusahaan yang mempengaruhi kemampuannya untuk melayani pelanggannya-perusahaan, pemasok, perusahaan saluran pemasaran, pasar pelanggan, pesaing dan masyarakat. Lingkungan makro terdiri dari kekuatan masyarakat lebih luas yang mempengaruhi lingkungan 
mikro-demografi, ekonomi, alam, teknologi, politik dan budaya). ${ }^{17}$

Faktor pendukung pemasaran MIMA or KH. Shiddiq adalah adanya ciri khas dalam melayani pelanggan (masyarakat) dan memudahkan lembaga dalam menjalin kepercayaan kepada masyarakat sehingga masyarakat berbondong-bondong datang ke MIMA o1 KH. Shiddiq Jember yang menyelenggarakan event tersebut. Adapun kendalanya adalah minimnya akses media social sehingga lembaga mempunyai program untuk terjun langsung kemasyarakat.

Berdasarkan paparan data di atas konsep perencanaan dan pelaksanaan pemasaran sekolah di MIMA or KH. Shiddiq Jember perlu dilakukan untuk memenuhi dan memberikan pelayanan yang prima kepada pelanggan (masyarakat). Dengan terdeteksi faktor pendukung dan kendala lembaga dapat menjadikan pemasaran sekolah menjadi pelengkap yang saling mengingatkan satu sama lain dengan tujuan seperti slogan Madrasah, yaitu: Madrasah Hebat Madrasah Bermartabat.

\section{Simpulan}

Berdasarkan papara di atas, ada tiga simpulan yang dapat dikemukakan. Pertama, perencanaan pemasaran MIMA or KH. Shiddiq Jember yang dibuat oleh Kepala Madrasah dan Panitia PPDB, yaitu dengan memperhatikan aspek: konsep produk (product), konsep harga (price), konsep promosi (promotion) dan konsep tempat (place). Kedua, pelaksanaan pemasaran sekolah dalam rekrutmen peserta didik baru di MIMA or KH. Shiddiq Jember menggunakan dua model. Pertama, identifikasi pasar dengan memperhatikan aspek: kekuatan (strengths), kelemahan (weaknesses), peluang (opportunities) dan ancaman (threats). Kedua, segmentasi pasar dan positioning, di antaranya: diferensi produk dan komunikasi pemasaran, yang meliputi: penjualan pribadi (personal selling), penjualan massal (mass selling), promosi penjualan (sales promotion, hubungan masyarakat (public relations), dan dari mulut ke mulut (word of mouth). Ketiga, faktor pendukung pemasaran madrasah ini adalah ciri khas pelayanan masyarakat, memudahkan lembaga dalam menjalin kepercayaan kepada masyarakat sehingga

${ }^{17}$ Phillip Kotler dan Gary Amstrong. Dasar-Dasar Pemasaran Jilid 1, (Jakarta: Prenhallindo, 1997), 70-71. 
masyarakat berbondong-bondong datang ke MIMA o1 KH. Shiddiq Jember yang menyelenggarakan event tersebut. Di lain pihak, kendala pemasarannya terdapat pada minimnya akses media sosial sehingga lembaga mempunyai program untuk terjun langsung ke masyarakat.

\section{Referensi}

Alma, Buchari dan Ratih Hurriyati, Manajemen Coorporate dan Strategi Pemasaran Pendidikan Fokus Pada Mutu dan Layanan Prima, Bandung: Alfabeta, 2008.

al-Razi, Fakhr al-Din, Tafsir al-Kabir wa Mafatih al-Ghaib Jilid 10, Beirut: Dar al Kutub al-Ilmiah, t.th.

Ath-Thabari, Abu Ja'far Muhammad bin Jarir, Jamiec Al- Bayan an Ta"wil Ayi Al-Qur'an. Penerjemah: Abdul Somad, Yusuf Hamdani, dkk., jilid 3, 12, 13, 21, Jakarta: Pustaka Azzam, 2008.

Davies, Brent dan Linda Ellison, School Development Planning, Essex: Longman Group, 1992.

Departemen Agama RI, Al-Qur'an dan Terjemahannya, Jakarta: Bumi Restu, 1976.

Heryati, Yeti dan Mumuh Muhsin, Manajemen Sumber Daya Pendidikan, Bandung: Pustaka Setia, 2014.

Hidayat, Ara dan Imam Machali, Pengelolaan Pendidikan Pertama, Bandung: Pustaka Educa, 2010.

Jefkins, Frank, Public Relations, Jakarta: Erlangga, 1995.

Kompri, Motivasi Pembelajaran Perspektif Guru dan Siswa, Bandung: Remaja Rosdakarya Offset, 2015.

Kotler, Phillip dan Gary Amstrong, Dasar-Dasar Pemasaran Jilid I, Jakarta: Prenhallindo, 1997.

Kotler, Phillip dan Kevin Lane Keller. Manajemen Pemasaran Edisi Ketiga Belas Jilid I, Jakarta : Erlangga, 2008.

Qomar, Mujamil, Manajemen Pendidikan Islam: Strategi Baru Pengelolaan Lembaga Pendidikan Islam, Jakarta: Erlangga, 2007. 